\title{
EFFECTIVE TEACHING-LEARNING TRANSACTION THROUGH ARCHAEOLOGY
}

\author{
Panda Sushanta Kumar
}

Department of Education, University of Jammu Jammu, India.

\begin{abstract}
Development of teacher education can be possible in two ways i.e. face to face or open distance learning. But development of teacher education depends on the proper teaching-learning transaction. For effective teaching-learning transaction it requires so many things like practice, teaching aids, field based knowledge, visit to museum, knowledge of history, culture and archaeology. The practice of archaeology has always had an educational component. No doubt with the help of archaeology past can be used to help us think productively about the present and future. Archaeology has the ability to bring communities together in a variety of meaningful ways. Through archaeology, one's national, cultural, and ethnic identity can be preserved and solidified which will be helpful for effective teaching-learning transaction directly and indirectly. There are different diversities in every country related to religion, caste, language, educational standard, and geographical conditions. Unity, equality and community development can be possible through the knowledge of archaeology. Even in the field of historical research, archaeological fieldwork technique along with fieldtrips and hands-on exercise has a great role to find out the realities, historical event and so on. Archaeology in the field of education including teaching and research should be the concern for teacher, researcher and learners for effective teaching learning transaction. In this connection, in curriculum the importance of archaeology should be mentioned for effective teaching learning transaction which will not only helpful for the development of formal education but also enhance the informal education. In a nutshell, the inclusion of archaeology in the educational field will be helpful for effective teaching-learning transaction.
\end{abstract}

Keywords: Archaeology, Effective Teaching, Higher Education, Teacher Education Programme, Internship.

\section{Introduction}

Teacher Education is not an old discipline like Economic, History, Political Science, Sociology, Psychology etc. Compared to most of the other countries, teacher education as a discipline in India is of recent origin and still in its infancy. Higher education and teacher education, at present, is developing fast with emerging new trends and subjects. Presently in India, total universities are 874 universities (47 central Universities, 391 state Universities, 125 Deemed to Be Universities and 311 Private Universities) as on 25th September 2018 (www.ugc.ac.in) and 621 autonomous colleges (170 Govt colleges and 451 Non Govt colleges) as on 8.9.2017. About 200 hundred universities offered teacher education programmes like Bachelor of Education (B.Ed) programme or M.Ed programme or both. Even some universities are offered B.Ed (both regular and open mode), BA-B.Ed, B.ScB.Ed and B.Ed-M.Ed integrated programmes. Teacher education is truly vital in creating the team of teachers that will shape the next generation. The teaching profession, like all high level service professions such as medicine and law - where people's lives are truly at stake and lie in the practitioner's hands - requires the very highest standards for education and training. Teacher preparation is an activity that requires multidisciplinary perspectives and knowledge, the formation of dispositions and values, and the development of practice under the best mentors. Teachers must be grounded in Indian values, ethos, knowledge, and traditions, while also being well-versed in the latest advances in education and pedagogy. Teacher education requires multidisciplinary inputs and a combination of high quality content and pedagogy that can only be truly attained if teacher preparation is conducted within composite multidisciplinary institutions. In India, different teacher education programmes are running which are given as under: 


\section{Diploma Programmes}

The Diploma Programs for Teacher Education includes.

Diploma in Early Childhood Education programme leading to Diploma in Pre-School Education (DPSE).

Elementary Teacher Education Programme leading to Diploma in Elementary Education (D.El.Ed.).

Diploma in Physical Education Programme leading to Diploma in Physical Education (D.P.Ed.).prestige and common purpose. History is enlarged by being disseminated; heritage is diminished and despoiled by export” (Lowenthal, 1998, p. 128).

Diploma in Elementary Education Programme through Open and Distance Learning System leading to Diploma in Elementary Education (D.El.Ed.).

Diploma in Arts Education (Visual Arts) programme leading to Diploma in Arts Education (Visual Arts).

Diploma in Arts Education (Performing Arts) programme leading to Diploma in Arts Education (Performing Arts).

Bachelor Programmes: The Bachelor Programs for Teacher Education includes

Bachelor of Elementary Teacher Education Programme leading to Bachelor of Elementary Education (B.El.Ed.) Degree.

Bachelor of Education Programme leading to Bachelor of Education (B.Ed.) Degree.

Bachelor of Physical Education Programme leading to Bachelor of Physical Education (B.P.Ed.) Degree.

Bachelor of Education Programme through Open and Distance Learning System leading to Bachelor of Education (B.Ed.) Degree.

Bachelor of Education Programme 3-year (Part Time) leading to Bachelor of Education (B.Ed) Degree.

Master Programmes: The Master Programs for Teacher Education includes

Master of Education Programme leading to Master of Education (M.Ed.) Degree.

Master of Physical Education Programme leading to Master of Physical Education

(M.P.Ed.) Degree. 


\section{Integrated Programmes:}

Four year Integrated Programme leading to B.A.B.Ed./B.Sc.B.Ed. Degree.

Three year Integrated Programme leading to B.Ed.-M.Ed. Degree.

In above teacher education programmes, internship is one of the integral parts like teaching practice, project work and reflective journal. Out of these teaching practice plays vital role for preparation of pupil- teachers. For effective teaching, requires some teaching aids like map, chart, historical picture, old things etc.. Generally old things are related to directly and indirectly archaeology. Archaeology is the study of the human past using material remains. These remains can be any objects that people created, modified, or used. With the help these things a pupil-teacher can teach effectively especially in social study subject. In above teacher education curriculum is related to archaeology directly and indirectly which is discussed in detail as under.

Archaeology is the study of remains of the past like skeletal remains, tools, artifacts etc. It is the study of the things created and used by the humans. In this, the past cultures and the way of living of humans are studied by archaeologists (people engaged in this profession). Artifacts are usually found buried in the ground. They are the things left on the ground which are covered by soil with time. Archaeology is the study of uncovering the roots of Human Civilization by investigating artifacts left behind by previous civilizations. Most people picture archaeologists digging up the earth with tools around them, but archaeology is much more than that. It has several branches; some of the more prominent ones are listed below. It is important to understand these branches before pursuing archaeology as a career path in India.

1. Historic Archaeology - This branch deals with discovering and analyzing ancient artifacts, such as items used in everyday life of people in different civilizations; Household Utensils, Jewelry, Musical or Medical equipment, etc.

2. Maritime Archaeology - The discovery of the lost city of Thonis- Heracleion, discovery of wrecked ships such as the Titanic are a few interesting examples of maritime archaeology. It tries to uncover the interaction of earlier humans with marine bodies.

3. Urban Archaeology - It deals with understanding the plans and maps of historical cities in order to determine their importance as well as predict what artifacts they may find while digging such locations. This branch has helped us in understanding the great planning and structural facets of great cities such as MohenjoDaro and Harappa.

4. Epigraphy - This branch of archaeology deals with identifying and analyzing inscriptions on documents, artifacts or stones in order to draw conclusions about their writers, their culture, and their historical importance.

5. Museology - It deals with organizing, preserving, and restoring museums as well as museum curacy. This segment of archaeology focuses on giving meaning to our existence through the display and preservation of historical artifacts. It is the route through which society understands its history.

Archaeology helps us to address some of the most fundamental questions about who we are and why we are the way we are. It is a very broad and dynamic subject that changes constantly with new discoveries and the development of new research techniques. Archaeology gets to grips with the physical remains of the past. It is well suited to students who are curious about human society and its past and who want to combine practical, hands-on work with traditional academic study. It is important that social studies teachers learn to teach social 
studies standards to both special needs and general learners. However, there is no single technique, approach or strategy that will accomplish this because of the complex nature of the Social Studies. The complexity rests in the diverse nature of the social studies, the wide variety of social studies teachers, the range of learning problems held by learners who are in social studies classrooms, and the many differences among the social studies standards themselves. However, general areas of advice can be offered to point teachers in the right direction. But the Social Studies related departments include: Anthropology, Economics, Geography, History, Political Science, Psychology and Sociology.

Social study is a branch of study which deals with human beings- their behaviour, growth and development, relationships, resources they use and the various institutions they require to function and carry on their life smoothly. It is the integrated study of the social sciences and humanities to promote civic competence. Within the school program, social studies provides coordinated, systematic study drawing upon such disciplines as anthropology, archaeology, economics, geography, history, law, philosophy, political science, psychology, religion and sociology, as well as appropriate content from the humanities, mathematics, and natural sciences. By providing vast comprehensive area, it enables the students to clear their relationship with their material, physical and social surroundings so that they are able to adjust themselves to the life of today. The primary purpose of social studies is to help young people develop the ability to make informed and reasoned decisions for the public good as citizens of a culturally diverse, democratic society in an interdependent world. Social Studies teachers become certified by taking a few hours of several courses in undergraduate work. If they are lucky, they then get a job, and become temporary specialists as they are assigned a particular course. Social studies involve ten themes. The teaching of some of these standards to both general and special populations varies from standard to standard. The themes are:

\section{Culture}

The study of culture deals with common characteristics of different cultures, belief systems and how they influence the rest of the culture, changing culture, and language. In schools this theme is usually addressed in classes dealing with geography, history, sociology, and anthropology as well as multicultural topics across the curriculum. Any difficulties in this area usually are related to reading comprehension. Attitudinally, the concept of ethnocentrism is difficult for most adults, so it is naturally a difficult concept for children of all learning abilities.

\section{Time, Continuity, and Change}

This is a history related theme which involves understanding historical roots and a person's position in time. It deals with what happened in the past and how I am connected to those in the past. Understanding the changing world helps explain events today and well as speculate about the future. Many learning difficulties in the history area, once again, revolve around reading comprehension. An issue particular to this theme, however, is the concept of historical time. Children are at a definite disadvantage when studying history because they just have not lived long enough to get a concept of time. This opens up possibilities for a teaching tool focusing on Timelines.

\section{People, Places, and Environments}

This geography-related theme assists students as they create their spatial views and geographic perspectives of the world outside their particular knowledge. The particular problems for all learners beyond the concepts of geographical perspective and reading comprehension have to do with graphic presentations. Special needs students have particular problems reading graphs, charts and maps. A Teacher tool addressing graphic presentations offers some solutions as special needs students need more time to understand these areas. 


\section{Individuals, Groups, and Institutions}

This is primarily a sociology/anthropology theme which also relates to psychology, political science and history. One issue involves understanding the influence of institutions on one's life, while the understanding of the nature of institutions and institutional change are addressed. This theme along with the Culture theme and Individual development theme offer opportunities for improved instruction using real examples and simulations of real events. Teacher tools involving personal realities and simulations are helpful for both general and special learners.

\section{Power, Authority, and Governance}

This political science theme involves the history and nature of power and the institutions of power. How are governments created, structured, maintained and changed? How can majority rule and minority rights be protected? This theme, along with the Civics theme: "The primary purpose of social studies is to help young people develop the ability to make informed and reasoned decisions for the public good as citizens of a culturally diverse, democratic society in an interdependent world." An ongoing learning problem for adults as well as all students is the concept of "common good" and the attitudinal issue of minority rights. Instruction improvement for general and special learners may involve connecting to the real world and experiencing processes through simulations.

\section{Production, Distribution, and Consumption}

Economics involves how goods are produced and distributed as well as the factors of production (land, labour capital, and management.). As a discipline, economics may be the most disparate from the others. Economics is a major part of the study of history and government, but has its own set of language and approach. Many social studies teachers are not comfortable with Economics. It involves the most practical, everyday issues, but addresses them in a highly abstract study. As with some other themes, the understanding of charts and graphs is a challenge for general, but particularly for special learners. Also, making the study real is useful in this area.

\section{Conclusion}

Archaeology education can also be judged by the perception and benefits received by the stakeholders of education, namely students, parents and employers. It is a matter of common knowledge and belief that proper growth of Archaeology education in the country depends on the quality of teaching, research and extension services. Archaeology education should be the top concern for academicians, administrators and the government. Archaeology is an effective teaching tool because its multidisciplinary basis enables focused or holistic approaches. It can be used to teach critical thinking skills, problem solving, and citizenship, and it enhances small group and cooperative learning. It is an excellent way to promote cultural awareness and sensitivity, which leads to an understanding of multicultural perspectives. Studying the past allows one to examine and project the consequences of human behavior and decision making.

\section{References}

Aggarwal, Y. (2017) How can I become an archaeologist in India? Retrieved from www Quora.com on 18.02.219

Slotman M.J. (2017) What's the Role of Archaeology in Education Curricula? Project Archaeology: Investigating a Shotgun House. Retrieved from www.google.com on 14.02.2019 
GOI (1986) National Policy on Education, New Delhi: MHRD

GOI (1992) National Policy on Education (Revised), New Delhi: MHRD

Khatri, S. (2016) Archaeology 101: Everything You Need To Know To Pursue This Exciting Career. Retrieved from https://www.mindler.com /blog/ archaeology-career-path-india/ on 1.2.2019

MHRD (2013) RUSA. Retrieved from http://mhrd.gov.in/higher_education. on 04.11.2018

MHRD (2019) Draft National Education Policy 2019. Retrieved from https://mhrd.gov.in/relevant-documents on 18.6.2019.

NCTE (2014) Teacher Education Programmes. Retrieved from http://ncte-india.org/ncte_new/ on 4.5.2015

Seevers John (-----) Strategies for Accessing the Social Studies Curriculum. The University of Kansas Lawrence, Kansas. Retrieved from http://www.specialconnections. $\mathrm{ku} . e d u /$ ?q=instruction/strategies_for_accessing_the_social_studies_curriculum on 03.01.2019

Society for America Archaeology (----) Why teach Archaeology? Retrieved from http://archeology.uark.edu/wp-content/uploads/2015/06/Why-Teach-Archeology.pdf on 12.02.2019,

UGC (2018) Consolidated list of Universities. Retrieved from www.ugc.ac.in on 12.11.2018. 
Proceeding of the International Conference on Archaeology, History and Heritage, Vol. 1, 2019, pp. 45-50 